\title{
The Relationship between Early Maladaptive Schemas of Cuts-Exclusion and Slip among Addicts Abusing Drugs under Methadone Maintenance Treatment
}

\author{
Elahe Mozaffari ${ }^{1}$, Mohamad Khaledian ${ }^{2, *}$, Fateme Taghavi ${ }^{3}$ \\ ${ }^{1}$ Fars Sciences and Research Branch, Islamic Azad University, Fars, Iran \\ ${ }^{2}$ Faculty of Psychology and Educational Sciences, Ghorveh Branch, Islamic Azad University, \\ Ghorveh, Iran \\ ${ }^{3}$ Department of Clinical Psychology, Payame Noor University, PO BOX 19395-3697 Tehran, Iran \\ *E-mail address: Mohamad_khaledian22@yahoo.com
}

\begin{abstract}
Nowadays, the addiction is considered as one of the main interests in the human life. Increasing trend of addiction results in several interests and problems for many countries and societies during past century. Indeed, addiction is a physical, mental, and social illness that there are several effective factors in its formation such as personal, inter-personal, environmental, and social factors. It is one of the most important factors in destroying citizens' health. In other words, addiction is a destructive and persistent illness that not only results in person's death, but also destroys his/her family and society. This study is a cross-sectional descriptive-analysis research. The authors of this study attempt to examine the relationship between early maladaptive schemas of cuts-exclusion and slip among addicts abusing drugs under methadone maintenance treatment. In order to select the sample members, about 200 patients (100 patients with slip and 100 patients without slip) were selected from patients in the public clinics of Shiraz city. The sample patients should have pass at least 6 weeks of their treatment period. The sampling method was convenience sampling method. In order to test the patients' positive or negative slip degree, they were under test monthly. A questionnaire and Young schema have been used for collecting the research data. The results of this study revealed that there is a significant relationship between abandonment scheme, distrust/misbehavior, defection/shame, social isolation/alienation, andextent of slip. Another part of the results revealed that there is not any significant relationship between emotional exclusion schema and extent of slip. With regard to the significant relationship between early maladaptive schemas and slip in the drug users that were under treat, it seems that the treatment scheme can be helpful in such patients for decreasing their slip and improving their health.
\end{abstract}

Keywords: Early Maladaptive Schemas; Slip; Methadone Maintenance Treatment

\section{INTRODUCTION}

The early maladaptive schemas as cognitive and emotional models are destructive factors that are created in beginning of growth and revolution stage in individuals' mind and are repeated during life time (Young et al., 2010). Indeed, schema is a long-term fixed model that is created in childhood period and continues to older periods. We see our surrounding 
environment through schemas. In other words, schemas are the important believes and feelings about self and environment that people understand and accept it without any force. On the other hand, schemas maintain themselves and prevents from any change (Yang, 2010). The early maladaptive schemas are most ancient cognitive believes and feelings and also emotions about ourselves that are created through balance between mental characteristics and parents' undesirable experiences in the early years of life (Yang, 1994). When these schemas are activated, can influence the deepest level of knowledge and awareness and also results in many psychological difficulties, addiction, depression, anxiety, and inefficient relations (Yang, 1999).United Nations Office for Drug Control and Crime Prevention reports that there are 200 million addicts with 15-64 years old across the world that about 1.8-3.3 million of them live in Iran.

Lotfi and Khosravi (2007), Wang et al. (2010), Dale et al. (2010), and Brummett (2007) pointed out that addicts have more maladaptive schemas and psychological difficulties in comparison to other normal individuals. The results of their studies revealed that there is much isolation in addicts that are under methadone maintenance treatment. Also Kazemi and Dide Roshan (2010) and Razavi et al. (2011) revealed in their study that the maladaptive schema is a normal phenomenon among addicts.

\section{RESEARCH METHODOLOGY}

\section{1. Statistical population, sample, and sampling method}

The statistical population of this study includes 1273 male addicts that were under methadone maintenance treatment in the city of Shiraz in 2012. A sample of 200 patients was selected from this population through convenience sampling method that 100 of them had slip and another 100 one had not any slip. Another characteristic of the sample members is that they are under treatment for at least 6 weeks.

\section{2. Data-collection method}

A researcher-developed questionnaire has been used for examining demographic characteristics of the sample members.

\section{3. The Young schema questionnaire-short form}

This questionnaire includes 75 items that has been developed by Young (1998) for evaluating 15 early maladaptive schemas. These include emotional exclusion, social isolation/instability, distrust/misbehavior, defection/shame, social isolation/alienation, failure, dependency/in-competency, vulnerability in front of any illness, obedience, sacrifice, emotional exclusion, strict criteria and fault, eligibility and gentlemanly, self-discipline, and insufficient self-discipline.

Smith et al. (1995) are the first authors that do a comprehensive study in terms of psychosocial characteristics of Young schema questionnaire. The results of the early maladaptive schema revealed that Cronbachs' Alpha coefficient of this questionnaire is 0.83 , 0.96, 0.50, 0.86 for different sections of this questionnaire (Young et al., 2010).

This scale has been normalized by Ahi (2005) in Iran. He reports that Cronbachs' Alpha coefficient was 0.97 for females and 0.98 for males. Also reliability of these schemas were calculated through Cronbachs' Alpha coefficient. These include 0.87 for emotional exclusion schema, 0.87 for social isolation/instability, distrust/misbehavior, defection/shame, social isolation/alienation, 0.87 failure, dependency/in-competency, 0.90 vulnerability in front of any 
illness, 0.89 emotional exclusion, 0.82 strict criteria and fault, eligibility and gentlemanly, and 0.87 for insufficient self-discipline.

\section{RESULTS}

The collected data has been analyzed through appropriate statistical methods. The results of this study have been presented in two sections including descriptive and inferential findings.

Table 1. The results of age distribution of the respondents.

\begin{tabular}{|c|c|c|}
\hline Variable & Slip & Slip-less \\
\hline Average & 36.97 & 40.54 \\
\hline Median & 35 & 38.5 \\
\hline Standard deviation & 9.69 & 10.96 \\
\hline The least age & 21 & 22 \\
\hline The most age & 65 & 63 \\
\hline
\end{tabular}

Table 2. Frequency, and percentage of the schemas among patients under methadone maintenance with slip and without slip.

\begin{tabular}{|c|c|c|c|c|c|}
\hline Variables & $\begin{array}{c}\text { Frequency } \\
\text { of slip }\end{array}$ & $\mathbf{\%}$ & $\begin{array}{c}\text { Frequency } \\
\text { of slip-less }\end{array}$ & $\mathbf{\%}$ & Sum \\
\hline $\begin{array}{c}\text { Instability and } \\
\text { exclusion }\end{array}$ & 56 & 60.9 & 36 & 39.1 & 92 \\
\hline Distrust & 47 & 66.2 & 24 & 33.8 & 71 \\
\hline Emotional exclusion & 45 & 58.4 & 32 & 41.6 & 77 \\
\hline Defection and shame & 23 & 69.7 & 10 & 30.3 & 32 \\
\hline Social isolation & 43 & 67.2 & 21 & 32.8 & 64 \\
\hline
\end{tabular}

The difference between patients with instability and exclusion distrust, emotional exclusion, defection and shame, social isolation is $21,32.4,16.8,39.4$, and 34.4 relatively. 
Table 3. The summary of statistical analysis.

\begin{tabular}{|c|c|c|c|}
\hline Schema & $\begin{array}{c}\text { Frequency in the } \\
\text { group with slip }\end{array}$ & $\begin{array}{c}\text { Frequency in the } \\
\text { group without slip }\end{array}$ & P \\
\hline Abandonment & 0.56 & 36.4 & 0.007 \\
\hline Distrust & 47.5 & 24.7 & 0.001 \\
\hline Emotional exclusion & 0.45 & 0.32 & 0.08 \\
\hline Defection/shame & 0.23 & 0.10 & 0.002 \\
\hline Social exclusion & 0.43 & 0.21 & 0.001 \\
\hline
\end{tabular}

The results of Table 3 indicate that there is a significant relationship between abandonment, distrust/misbehavior, defection/shame, and social exclusion/alienation with extent of slip. But there is not any significant relationship between emotional exclusion schema and extent of slip among male addicts under methadone maintenance treatment.

Hypothesis 1: there is a significant relationship between emotional exclusion schema and extent of slip among male addicts under methadone maintenance treatment.

Table 4. The results of frequency and relative frequency of emotional exclusion schema among patients with and without schema.

\begin{tabular}{|c|c|c|c|c|c|}
\hline Variable & $\begin{array}{c}\text { Frequency } \\
\text { of patients } \\
\text { with slip }\end{array}$ & $\%$ & $\begin{array}{c}\text { Frequency } \\
\text { of patients } \\
\text { without slip }\end{array}$ & $\%$ & Sum \\
\hline With schema & 45 & $58.4 \%$ & 32 & $41.6 \%$ & 77 \\
\hline $\begin{array}{c}\text { Without } \\
\text { schema }\end{array}$ & 55 & $44.7 \%$ & 68 & $55.3 \%$ & 123 \\
\hline
\end{tabular}

With regard to the results of Table 4, 77 patients from 200 sample members had emotional exclusion schema. This consists $58.4 \%$ of the statistical population. On the other hand, 123 ones had not such as schema and 55 ones $(44.7 \%)$ of them had not any slip. The difference is not significant from statistical perspective. This means that there is not any significant relationship between schemas.

Hypothesis 2: there is a significant relationship between exclusion schema and extent of slip among male patients with methadone maintenance treatment. 
Table 5. The results of frequency and relative frequency of abandonment exclusion schema among patients with and without schema.

\begin{tabular}{|c|c|c|c|c|c|}
\hline Variable & $\begin{array}{c}\text { Frequency of } \\
\text { patients with } \\
\text { slip }\end{array}$ & $\%$ & $\begin{array}{c}\text { Frequency of } \\
\text { patients without } \\
\text { slip }\end{array}$ & $\%$ & Sum \\
\hline With schema & 56 & $60.9 \%$ & 36 & $39.1 \%$ & 92 \\
\hline $\begin{array}{c}\text { Without } \\
\text { schema }\end{array}$ & 44 & $41.1 \%$ & 63 & $58.6 \%$ & 107 \\
\hline
\end{tabular}

The results of Table 5 showed that 92 members of sample had exclusion schema that 56 ones of them (60.9\%) had slip and other 107 ones had not such as schema. This difference is significant in 0.05 . Therefore, the hypothesis is supported and it can be said that there is a significant relationship between exclusion schema and extent of slip.

Hypothesis 3: there is a significant relationship between distrust/misbehavior and the extent of slip among patients under methadone maintenance treatment.

Table 6. The results of frequency and relative frequency of distrust/misbehavior schema among patients with and without schema.

\begin{tabular}{|c|c|c|c|c|c|}
\hline Variable & $\begin{array}{c}\text { Frequency of } \\
\text { patients with } \\
\text { slip }\end{array}$ & $\%$ & $\begin{array}{c}\text { Frequency of } \\
\text { patients without } \\
\text { slip }\end{array}$ & $\%$ & Sum \\
\hline With schema & 47 & $66.2 \%$ & 24 & $33.8 \%$ & 71 \\
\hline $\begin{array}{c}\text { Without } \\
\text { schema }\end{array}$ & 52 & $41.6 \%$ & 73 & $58.4 \%$ & 125 \\
\hline
\end{tabular}

The results of Table 6 revealed that 71 ones of sample members had distrust/misbehavior schema and 47 ones of them had slip. On the other hand, from 125 ones that had not any schema, 52 had slip. This difference is not significant considerably. This means that there is not any significant relationship between distrust/misbehavior and extent of slip.

Hypothesis 4: there is a significant relationship between social exclusion/alienation and the extent of slip among patients under methadone maintenance treatment.

Table 7. The results of frequency and relative frequency of social exclusion/alienation schema among patients with and without schema.

\begin{tabular}{|c|c|c|c|c|c|}
\hline Variable & $\begin{array}{c}\text { Frequency } \\
\text { of patients } \\
\text { with slip }\end{array}$ & $\%$ & $\begin{array}{c}\text { Frequency } \\
\text { of patients } \\
\text { without slip }\end{array}$ & $\%$ & Sum \\
\hline With schema & 43 & $67.2 \%$ & 21 & $32.8 \%$ & 64 \\
\hline $\begin{array}{c}\text { Without } \\
\text { schema }\end{array}$ & 57 & $41.9 \%$ & 79 & $58.1 \%$ & 136 \\
\hline
\end{tabular}


As the results of Table 7 revealed, 65 ones of the sample members who had social exclusion/alienation had slip. On the other hand, the results indicated that 136 ones of the sample members had not any schema that 57 ones of them had slip. This difference is significant statistically. Therefore, it can be said that there is a significant relationship between social exclusion/alienation and slip among patients methadone maintenance treatment.

Hypothesis 5: there is a significant relationship between defection/shame and the extent of slip among patients under methadone maintenance treatment.

Table 8. The results of frequency and relative frequency of defection/alienation schema among patients with and without schema.

\begin{tabular}{|c|c|c|c|c|c|}
\hline Variable & $\begin{array}{c}\text { Frequency of } \\
\text { patients with } \\
\text { slip }\end{array}$ & \% & $\begin{array}{c}\text { Frequency of } \\
\text { patients } \\
\text { without slip }\end{array}$ & $\%$ & Sum \\
\hline With schema & 23 & $69.7 \%$ & 10 & $30.3 \%$ & 33 \\
\hline $\begin{array}{c}\text { Without } \\
\text { schema }\end{array}$ & 77 & $46.1 \%$ & 90 & $53.9 \%$ & 167 \\
\hline
\end{tabular}

The results of hypothesis 5 that have been presented in Table 8 , it can be concluded that 33 ones of the sample members had defection/shame schema that 23 ones of them had slip. On the other hand, 167 ones of the sample members had not any defection/shame schema. 77 ones of these 167 respondents had slip. Therefore, it can be said that there is a significant relationship between defection/shame schema and extent of slip.

\section{DISCUSSION AND CONCLUSION}

The purpose of this was to examine the relationship between early maladaptive schemas and slip among patients under methadone maintenance treatment. The results of this study revealed that there is not any significant relationship between emotional exclusion schema and the extent of slip. This result is supported by Dide Roshani (20110), Shari et al. (2011), and Young et al. (1998). It can be concluded that the patients with such schemas do not expect that their tendency to emotional relationship with other be satisfied fully. The family supports child in every culture and such a support every person to satisfy his/her needs and has not any slip during time. On the other hand, any relationship has not been observed between emotional exclusion schema and slip. Such people solve their problem through maladaptive avoidance strategy. Also the results showed that there is a significant relationship between abandonment of the patients under methadone maintenance treatment. The result of this part is supported by Ball (1998), Brummet (2007), and Kazemi and Dide Roshan (2010). It can be said that the patients who have such a schema believe that there is not any stability in their relations with others. They also believe that their family will abandon them and will not support and encourage them. Becauseof the relatives' in-attention to the patients with methadone maintenance treatment results in more stress and difficulties for them, they will be very vulnerable. Lack of control on such interests can encourage people to solve these problems and help them to decrease such fear and interests. Finally, the patient may select an ancient incorrect solution because of its partial relaxation. On the other hand, there is a significant relationship between distrust/misbehavior and extent of slip among patients under methadone maintenance treatment. 
This result is supported by Ball (1998) and Brummett (2007). It seems that patients with such as a schema believe that other abuse them and miss their opportunities in every time. Such expectations lead that patient perceives surrounding environment especially and perceive every damage as considerable damage. Also the results revealed that there is a significant relationship between defection/shame schema and extent of slip among patients under methadone maintenance treatment. This result is in consistency with findings of Ball (1998), Brummett (2007), and Kazemi and Dide Roshan (2010). The patients who have this schema feel that are fault, bad, humble one. They also believe that they are undesirable and unpopular ones for their relatives and family members. This is why that they have much sensitivity toward exclusion, crisis, shame, unsafely sense, and timidity in front of others. The final part of the results revealed that there is a significant relationship between social exclusion/alienation and extent of slip among patients under methadone maintenance treatment. This part of the results is in consistency with findings of Ball (1998), Brummett (2007), and Kazemi and Dide Roshani (2010). The patients with social exclusion/alienation schema believe that are different from others. Because they feel that have not any belonging to others and have not any friend, they will be encouraged to abuse drugs.

With regard to the results of this study in terms of the relationship between early maladaptive schemas and slip among patients under methadone maintenance treatment, it is suggested that the future studies concentrates on the effectiveness of treatment schema on decreasing their slip. Also it is suggested that the future studies concentrates on the family style of these patients and its relationship with parenting methods and also its effects on the slip and drug abuse will be studied in the future studies. It will be helpful if the future studies can offer solutions for solving the addiction problem based on the schema perspective. The results of such studies can be helpful in treating addicts.

\section{References}

[1] Ball S. A., Addicted Behaviors 23(6) (1998) 884-886.

[2] Brummett B. R., Attachment, Style, Early Maladaptive Schemas, Coping Self-efficacy Therapy Alliance and Their Influence on Addiction Severity In Methadone-maintenance Treatment. University of Network. 2007, 56, 98.

[3] Dale R, Power K, Kane S, et al., Arch Suicide Res. 14(4) (2010) 311-28.

[4] Kameli Zahra, Ghanbari Hashem, Abadi Bahram, Mohamadian Sheerbaf, Hamid Agha, Examining the effectiveness of cognitive treatment methods based on the schemas for moderating early maladaptive schemas, Journal of researches in clinical psychology and consulting 1 (2009).

[5] Kazemi, Reza, Dide Roshan, Sonia. The comparison of early maladaptive schema and mental health among addicts and normal individuals 16(3) (2010).

[6] Lotfi, Razie, Donyavi, Vahid, Khosravi, Zohre, Journal of Medical University 2 (2007) 1261-1266.

[7] Maref Vand, Masoume, Ghlima, Mostafa, Rahgozar, Mahdi, Tadayoun, Nazanin, Deylamizade, Abbas, Ekhtiari, Hamed. The social-based prevention from addiction: a cooperative action, Journal of social research 4 (2011). 
[8] Razavi, Vida, Soltani Nejhad, Ali, Rafei, Afson. The comparison of early maladaptive schemas in the addictive patients of Kermand city, Journal of medical researches of Zahedan University (2011).

[9] Shargh Ali, Shakibi Ali, Neysari Alino, Leyla. Examines the effective factors on addiction from addicts' perspective, Journal of Urmia Physician 9(31) (2011).

[10] Shorey R. C., Stuart G. L., Anderson S. The Early Maladaptive Schemas Of Opioid Dependent Sample of Treatment Seeking Young Adults: A Descriptive Investigation. Journal of Substance Abuse Treatment (2011) 5.

[11] Thimm J. C., Personality and Early Maladaptive Schemas: A Five Factor Model Perspective. Behavior Therapy and Experimental Psychiatry (2010) 374.

[12] Wang C. E., Halvorsen M., Eisemann M., Waterloo K., Behavior Therapy and Experimental Psychiatry 41(4) (2010) 389-96.

[13] Yang J. (2010). The treatment cognition of personality disorders based on the schemabased approach, translated by Sahebi and Vahidpor to Persian, Tehran: Agah Arjmand publications.

[14] Yang J., Klosko Jaunt, Vishar Marjori, (2010). The treatment schema: a practical guidance for clinical experts, translated by Hamidpor and Andoz to Persian, Arjmand publications.

[15] Zaree Iraj (2010). Determines the effectiveness of group treatment on the personality disorders among addicts, M.A. Thesis, Fars sciences and research branch, Islamic Azad University. 